\title{
Significant Neurological Manifestations During Pandemic COVID-19: A Review
}

\author{
Fransisca Kristina Elisabet ${ }^{1}$ \\ ${ }^{1}$ Research Assistant at Infectious Disease (TB/HIV) Research Center, Padjadjaran University, \\ Jl. Prof. Eyckman No. 38, Bandung, Indonesia \\ fransiscakristina24@gmail.com
}

\begin{abstract}
The outbreak of coronavirus disease 2019 (Covid-19) was first identified in Wuhan, China, in early December 2019. In the past few months, it has spread rapidly all over the world. This pandemic is an unprecedented worldwide health crisis and has shaken the core of the medical health system. Covid-19 is caused by SARS-CoV-2, a highly infectious pathogen that is genetically similar to SARS-CoV. Apart from the typical respiratory symptoms, significant neurological manifestations are being recognized increasingly in Covid-19 patients involving the central and peripheral nervous system. It could be involved resulting in a wide variety of manifestations started from headache, dizziness, anosmia, dysgeusia, impaired consciousness, to specific neurological diseases such as cerebral infarction, meningitis, encephalitis, Guillain-Barré syndrome, and painful neuropathy. Novel clinical trial designs need to be considered since the virus has attacked the nervous system in various aspects. This paper aims to review the possibility of neurological symptoms involvement in Covid-19 in order to understand the pathogenesis potential of this virus in the nervous system. By doing so, we could manage and prevent the long term effects of Covid-19 patients with neurological manifestations.
\end{abstract}

Keywords: Coronavirus, Neurological Manifestations, and Nervous System

\section{Introduction}

Since the emerging of the severe acute respiratory syndrome coronavirus-2 (SARS-CoV-2) infection in Wuhan, China, in the end of 2019, the coronavirus disease 2019 (Covid-19) has consequently sparked a global pandemic for months. ${ }^{1}$ As of $14^{\text {th }}$ January 2021 , this virus has led to over 90.7 million confirmed infections and almost 1.9 million deaths from coronavirus disease-2019 (Covid-19) worldwide. $^{2}$ In Indonesia, the number of Covid-19 positive cases continue to increase up to 869.600 with a $2.9 \%$ case fatality rate. ${ }^{3}$ As for Covid-19, several studies have described typical clinical manifestations include fever, cough, diarrhea, and fatigue. The Covid-19 disease also has characteristic laboratory findings and lung computed tomography (CT) abnormalities. ${ }^{4}$ However, a rapidly accumulating set of clinical studies revealed typical symptoms of Covid-19 that involve neurological signs, including headache, dizziness, anosmia, dysgeusia, damage to respiratory centers, and cerebral infarction (Figure 1)..$^{5-7}$

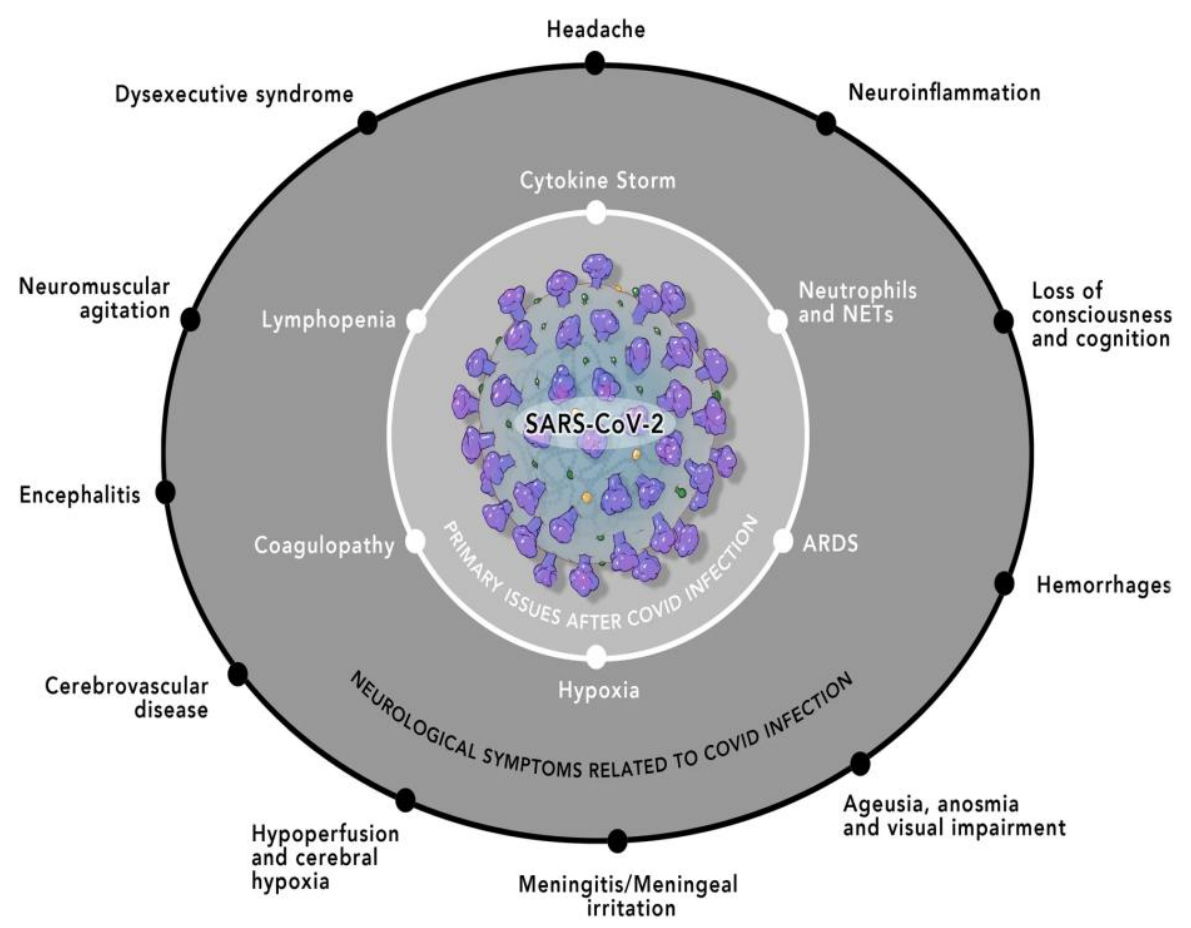

Figure 1: Schematic illustration of COVID-19-related symptoms. Primary issues associated with COVID-19 are shown within the inner circle (see white text). These symptoms are widely reported in a large majority of patients infected with Covid-19. The outer circle (see black text) depicts neurological issues/symptoms that have been reported after Covid-19.

Volume 10 Issue 1, January 2021 www.ijsr.net 
Indeed, a wide range of neurological manifestations of Covid-19 infection have been recognized, and evidence of their severity and persistence is increasing. ${ }^{8-9}$ The pathogenesis potential of Covid-19 in the nervous system remains unclear ${ }^{10}$, and the range of neurological disorders associated with Covid-19 is not fully defined. This paper aims to provide a comprehensive overview of neurological manifestations associated with Covid-19 (SARS-CoV-2) infection and analyze their potential mechanisms of the nervous system damage.

\section{SARS-CoV-2 versus Nervous System}

Several studies suggest that the human coronavirus namely HCoV-229E, HCoV-OC43, Severe Acute Respiratory Syndrome Coronavirus 1 (SARS-CoV-1), and Middle East Respiratory Syndrome Coronavirus (MERS-CoV) might involve the nervous system. For instance, in a post-mortem study of the brains of patients with multiple sclerosis, $\mathrm{HCoV}-229 \mathrm{E}$ and HCoV-OC43 has been detected, suggesting neuro-invasion by these viruses. ${ }^{11}$ However, this could also be due to a disturbance in the Blood Brain Barrier (BBB); further studies would be required to distinguish between opportunistic and disease-associated viral presence. In cellbased studies, astrocytes, oligodendrocytes, neurons, and microglia were susceptible to infection by $\mathrm{HCoV}-\mathrm{OC} 43 .^{12}$ Polyneuropathy, myopathy, rhabdomyolysis, and large artery ischemic stroke have also been reported in a few patients with SARS-CoV-1. ${ }^{13}$ The SARS-CoV-1 has been detected in the cerebrospinal fluid (CSF) of some patients, and an autopsy study found SARS-CoV-1 in the brain. ${ }^{14}$ Arabi et al. (2017) reported the presence of MERS-CoV in three patients with encephalitis. ${ }^{15}$ Compared with MERS-CoV, there are more reports of neurological manifestations with SARS$\mathrm{CoV}-1$. There is a high similarity between the genomes and cell entry mechanisms of SARS-CoV-1 and SARS-CoV-2, and thus raising the possibility of neurological involvement in Covid-19.

The possible pathway of penetration of the Covid-19 into the nervous system could be either hematological or through the peripheral nerves. ${ }^{16}$ SARS-CoV-2 particles have already been identified in capillary endothelia and neurons of frontal lobe brain sections in an autopsy of a Covid-19 patient, corroborating this hypothesis. ${ }^{17}$ In the hematological route of entry, the Covid-19 either enters the leukocytes or the bloodstream and also to the blood through the mucosa. Many viruses can breach the Blood Brain Barrier (BBB). The BBB in a healthy state prevents the breach by pathogens. However, if there is immunosuppression and inflammation, invasion of viruses can occur. Clinical and experimental animal studies report that the neuro-invasive potential of coronavirus spread from the respiratory tract to Central Nervous System (CNS) occurs via retrograde axonal transport from peripheral nerves, such as the olfactory nerve, or through the hematogenous pathway (Figure 2). ${ }^{18}$ The olfactory nerve is mainly held responsible for the infection of the CNS through the neuronal pathway due to its proximity to the nasal cavity, a common locus of virus infection, and the communication of the nasal epithelium with the olfactory bulb, through the cribriform plate of the ethmoid bone, thereby allowing the entrance of the virus. ${ }^{19-20}$ Supporting this hypothesis, a recent report presents the magnetic resonance imaging of Covid-19 patient brain, demonstrating anosmia. ${ }^{21}$ From this observation, it shows signal alteration in the olfactory bulbs and frontal lobe of a patient with anosmia with SARS-CoV-2 infection. After the disappearance of the symptoms, the control image is normal. $^{21}$

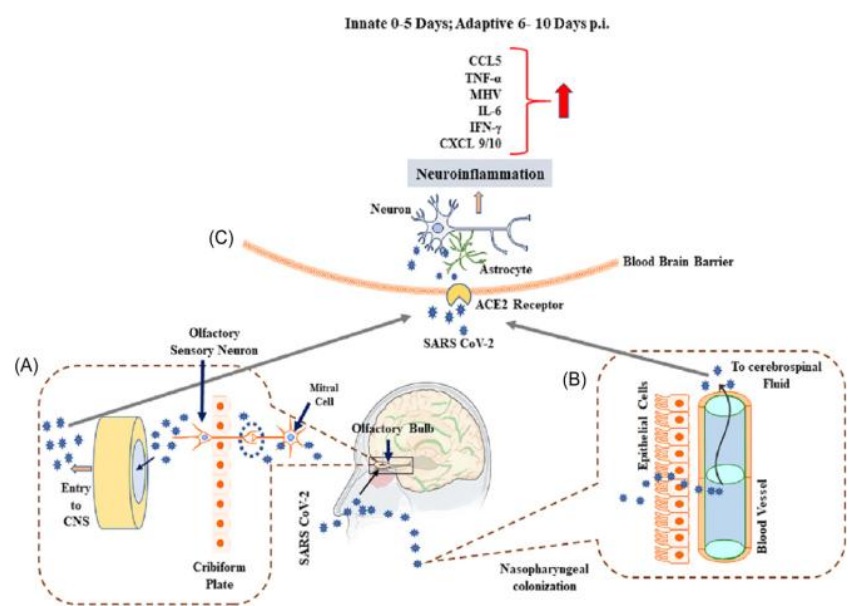

Figure 2: Possible entry routes of SARS-CoV-2 into brain, (A) Describe entry of SARS-CoV-2 from nasal epithelium to olfactory bulb entering CNS, (B) Explain entry of SARS-

$\mathrm{CoV}-2$ from the nasopharyngeal region to cerebrospinal fluid, thus gaining access to CNS, (C) Describe binding of SARS-CoV-2 to ACE-2 receptors on the endothelial cells of BBB thus invading CNS and stimulating the cytokine storm by binding to ACE-2 receptors on the glial cells and neurons.

*ACE-2: Angiotensin Converting Enzyme 2, BBB: Blood Brain Barrier, CNS: Central Nervous System

\section{Neurological Manifestations by SARS-CoV- 2 (Covid-19)}

As the Covid-19 pandemic progresses, reports of the patient with neurological manifestations have seen increasingly. Most viral infections begin in the peripheral tissues. Despite protective barriers and the immune systems, viruses could invade the nervous system through the bloodstream or infect the nerves connecting to the peripheral tissues. ${ }^{22,30} \mathrm{~A}$ recent study has reported SARS-CoV-2 infection of the brain, causing disturbances in the mental health of the patients with Covid-19. ${ }^{23,28}$ At the same time, an increase in symptoms like anxiety and depression are expected during the circumstances and restrictions of the global pandemic.

Given that SARS-CoV-2 causes a large number of asymptomatic or mildly symptomatic infections, it is crucial to remember that patients with neurological diseases from other causes might be infected coincidentally with the virus, including in-hospital through the nosocomial transmission. A full investigation, which is absent in many reports to date, is needed to rule out other established causes of brain infections before attributing diseases to Covid-19. ${ }^{24-25}$ Distinguishing between nasopharyngeal SARS-CoV-2 infection and nervous system infection is also key. A cohortbased study on neurological manifestations of Covid-19 has 
been reported. In this retrospective study of 214 Covid-19 patients in Wuhan, China, 36.4\% suffered from neurological symptoms. ${ }^{6}$ The researchers and neurologists analyze the data and categorize the symptoms into three categories. If the Central Nervous System (CNS) have been affected, the patients developed symptoms such as dizziness, headache, impaired consciousness, acute cerebrovascular disease, ataxia, and seizure. Patients with affected Peripheral Nervous System (PNS) have clinical manifestations including taste, smell, and vision impairment as well as nerve pain. ${ }^{6}$

The final category is for patients who have suffered sustained-injury to their skeletal-muscular system. Patients who have more severe infections, as well as those who are older and have other underlying disorders such as hypertension, are more likely to have these neurological symptoms. Patients with more severe infections were $5.1 \%$ more likely to have acute cerebrovascular diseases, $12.4 \%$ more likely to have impaired consciousness, and $14.5 \%$ more likely to have a skeletal muscle injury. ${ }^{6,29}$

Recent literature has reported cases of Guillain-Barré Syndrome (GBS) as a complication of the novel coronavirus. $^{26-27}$ GBS is a polyneuropathy that commonly develops post-infection. Immune attack of nerve cells causes the typical tingling in the extremities that is commonly reported as being the first symptom of GBS. Little is known about the interaction between SARS-CoV-2 infection and GBS. However, clinicians should be aware of the possibility of GBS complication when treating patients who have tested positive for SARS-CoV-2. Table 1 summarizes the common neurological manifestations in the Covid-19.

Table 1: Cohort Studies on Neurological Manifestations in the Covid-19

\begin{tabular}{|c|c|c|c|c|c|c|c|c|}
\hline Study & $\mathrm{N}$ & $\begin{array}{l}\text { Headache } \\
\text { (\%) }\end{array}$ & $\begin{array}{l}\text { Dizziness } \\
(\%)\end{array}$ & $\begin{array}{l}\text { Impaired } \\
\text { consciousness } \\
(\%)\end{array}$ & $\begin{array}{l}\text { Acute } \\
\text { cerebrovascular } \\
\text { disease }(\%)\end{array}$ & $\begin{array}{l}\text { Skeletal } \\
\text { muscle } \\
\text { injury (\%) }\end{array}$ & $\begin{array}{l}\text { Ataxia } \\
(\%)\end{array}$ & $\begin{array}{l}\text { Seizure } \\
(\%)\end{array}$ \\
\hline Li et al. ${ }^{8}$ & 221 & NA & NA & NA & 5.8 & NA & NA & NA \\
\hline Mao et al. ${ }^{6}$ & 214 & 13.1 & 16.8 & 7.5 & 2.8 & 10.7 & 0.5 & 0.5 \\
\hline Qin et al. ${ }^{9}$ & 452 & 11.4 & 8.1 & NA & NA & NA & NA & NA \\
\hline Helms et al. ${ }^{7}$ & 58 & NA & NA & NA & $23(3 / / 3)^{a}$ & NA & NA & NA \\
\hline Wang et al. ${ }^{10}$ & 138 & 6.5 & 9.4 & NA & NA & $34.5^{b}$ & NA & NA \\
\hline
\end{tabular}

COVID-19: coronavirus disease 2019; N: number of patients; NA: not analyzed (all studies were conducted in 2020); MRI: magnetic resonance imaging. aBrain MRI scans were done in 13 patients and cerebral ischemic stroke was identified in three. bOnly myalgia was considered.

\section{Conclusion and Future Recommendation}

SARS-CoV-2 primarily affects the respiratory and cardiovascular system. However, it might affect the nervous system as well, and there is a lot of evidence to suggest that multiple cytokine expression profiles are involved in the initial host's immune response to the infection, which might lead to immune impairment in the brain. Neurological involvement is not uncommon and could impact in serious complications if not detected and managed early and properly. Therefore, a high index of suspicion is required while dealing with the cases for prompt treatment and prevention. Further cohort studies about neurological involvement in the Covid-19 are necessary to be performed in a larger number of patients on a multicenter basis. Current advanced technology such as brain imaging, electroencephalography (EEG), cerebrospinal fluid (CSF) analysis, and histopathology might also help and provide a better understanding of the effect of SARS-CoV-2 in the nervous system.

\section{References}

[1] Chen N, Zhou M, Dong X, Qu J, Gong F, Han Y, "Epidemiological and Clinical Characteristics of 99 Cases of 2019 Novel Coronavirus Pneumonia in Wuhan, China: a Descriptive Study", The Lancet Journal, XIII, 2020.

[2] World Health Organization (WHO), "WHO Coronavirus Disease (COVID-19) Dashboard" [Online]. Available: https://covid19.who.int/. [Accessed: Jan. 14, 2021].
[3] Indonesia Covid-19 Site, "Gugus Tugas Pecepatan Penanganan COVID-19 Dashboard" [Online]. Available: https:// www.covid19.go.id/). [Accessed: Jan. 14, 2021].

[4] Guan W, Ni Z, Hu T, Liang WH, Ou CQ, He JX, "Clinical Characteristics of Coronavirus Disease 2019 in China", The New England Journal of Medicine, 2020.

[5] Yan CH, Faraji F, Prajapati DP, Boone CE, De Conde AS, "Association of Chemosensory Dysfunction and COVID-19 in Patients Presenting with Influenza-like Symptoms", International Forum of Allergy \& Rhinology pp. 10(7):806-13, 2020.

[6] Mao L, Jin H, Wang M, Hu Y, Chen S, He Q, "Neurological Manifestations of Hospitalized Patients with Coronavirus Disease 2020 in Wuhan, China", JAMA Neurology Journal, 2020.

[7] Helms J, Kremer S, Merdji H, Clere-Jehl R, Schenck M, Kummerlen C, "Neurologic Features in Severe SARS-CoV-2 Infection", The New England Journal of Medicine, 2020.

[8] Berger JR, "COVID-19 and the Nervous System, Journal of Neurovirology, pp. 26:143-148, 2020.

[9] Carfì A, Bernabei R, Landi F, Group ft GAC-P-ACS, "Persistent Symptoms in Patients after Acute COVID-19”, JAMA Neurology Journal, 2020.

[10] Zubair AS, McAlpine LS, Gardin T, Farhadian S, Kuruvilla DE, Spudich S, "Neuropathogenesis and Neurologic Manifestations of the Coronaviruses in the Age of Coronavirus Disease 2019: A Review. JAMA Neurology Journal, 2020. 
[11] Arbour, N, Day, R, Newcombe, J, "Neuroinvasion by Human Respiratory Coronaviruses", Journal of Neurovirology, pp. 74: 8913-8921, 2020.

[12] Arbour, N, Côté, G, Lachance, C, “Acute and Persistent Infection of Human Neural Cell Lines by Human Coronavirus OC43", J Neurovirol pp. 73: 3338-3350, 2020.

[13] Tsai, LK, Hsieh, ST, Chang, YC, "Neurological Manifestations in Severe Acute Respiratory Syndrome", Acta Neurol Taiwan, pp. 14(3): 113-119, 2005.

[14] Ding, Y, He, L, Zhang, Q, "Organ Distribution of Severe Acute Respiratory Syndrome (SARS) Associated Coronavirus (SARS-CoV) in SARS patients: Implications for Pathogenesis and Virus Transmission Pathways", The Journal of Pathology, pp. 203: 622-630, 2004.

[15] Arabi, YM, Balkhy, HH, Hayden, FG, "Middle East Respiratory Syndrome", The New England Journal of Medicine, pp. 376: 584-594, 2017.

[16] DosSantos MF, Devalle S, Aran V, "Neuromechanisms of SARS-CoV-2: A Review", Frontiers in Neuroanatomy Journal, 2020.

[17] Paniz-Mondolfi A, Bryce C, Grimes Z, Gordon RE, Reidy J, Lednicky J, “Central Nervous System Involvement by Severe Acute Respiratory Syndrome Coronavirus-2 (SARS-CoV-2)", J Med Virol, pp. 92(7):699-702, 2020.

[18] Desforges M, Le Coupanec A, Dubeau P, "Human Coronaviruses and Other Respiratory Viruses: Underestimated Opportunistic Pathogens of the Central Nervous System", Elsevier Journal, 2020.

[19] Desforges M, Le Coupanec A, Stodola JK, MeessenPinard M, Talbot PJ, "Human Coronaviruses: Viral and Cellular Factors Involved in Neuroinvasiveness and Neuropathogenesis", Virus Res, pp.194:145-158, 2014.

[20] Netland J, Meyerholz DK, Moore S, Cassell M, Perlman S, "Severe Acute Respiratory Syndrome Coronavirus Infection Causes Neuronal Death in the Absence of Encephalitis in Mice Transgenic for Human ACE2", Journal of Virology, pp.82(15):7264-7275, 2018.

[21] Politi LS, Salsano E, Grimaldi M, "Magnetic Resonance Imaging Alteration of the Brain in a Patient with Coronavirus Disease 2019 (COVID-19) and Anosmia", JAMA Neurology Journal, 2020.

[22] Koyuncu OO, Hogue IB, Enquist LW, "Virus Infections in the Nervous System", Cell Host Microbe, pp.13:379-393, 2013.

[23] Holmes EA, O'Connor RC, Perry VH, Multidisciplinary Research Priorities for the COVID19 Pandemic: Call for Action for Mental Health Science, Lancet Psychiatry Journal, pp.7:547-560, 2020.

[24] Solomon T, Michael BD, Smith PE, "Management of Suspected Viral Encephalitis in Adults-Association of British Neurologists and British Infection Association National Guidelines, Journal of Infection, pp. 64:34773, 2012.

[25] Yan R, Zhang Y, Li Y, Xia L, Guo Y, Zhou Q, "Structural Basis for the Recognition of SARS-CoV-2 by Full-length Human ACE2", Journal of Science, pp. 367: 1444-48, 2020.

[26] Coen M, Jeanson G, Alejandro Culebras Almeida L, et al. Guillain-Barré Syndrome as a Complication of SARSCoV- 2 Infection. Brain Behav Immun, 2020.

[27] Otmani H, El Moutawakil B, El Rafai, "Covid-19 and Guillain-Barré Syndrome”, Revue Neurologique, 2020.

[28] Liu K, Pan M, Xiao Z, Xu X, "Neurological Manifestations of the Coronavirus (SARS-CoV-2) Pandemic 2019-2020, Journal of Neurosurgery and Psychiatry, 2020.

[29] Li, Y, Li, M, Wang, M, “Acute Cerebrovascular Disease Following COVID-19: a Single Center, Retrospective, Observational Study", Stroke Vascular Neurology Journal, 2020.

[30] Qin, C, Zhou, L, Hu, Z, "Dysregulation of Immune Response in Patients with COVID-19 in Wuhan, China", Clinical Infectous Disease Journal, pp. 71: 762-768, 2020.

[31] Helms, J, Kremer, S, Merdji, H, "Neurologic Features in Severe SARS-CoV-2 Infection. The New England Journal of Medicine, pp.382: 2268-2270, 2020.

[32] Wang, D, Hu, B, Hu, C, "Clinical Characteristics of 138 Hospitalized Patients with 2019 Novel Coronavirus-Infected Pneumonia in Wuhan, China”, JAMA Neurology Journal, pp.323:1061-1069, 2020.

\section{Author Profile}

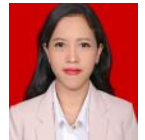

Fransisca Kristina Elisabet received MD degree in Faculty of Medicine, Maranatha Christian University (2017). Worked as a General Practitioner (GP) for various hospitals in Indonesia (2017-2019), such as Pertamina Hospital Balikpapan, Siloam Hospital Balikpapan, Medika Utama Permata (RSPKT Group) Hospital, and as a medical check-up doctor in Indomec Clinic Balikpapan. Currently, she is working as a Research Assistant in Infectious Disease (TB-HIV) Research Center, Faculty of Medicine, Padjadjaran University (2021) to involve in Indonesia Brain Infection Study. 